\title{
Novel GLP-1 analog supaglutide improves glucose homeostasis in diabetic monkeys
}

\author{
Qiaoli Cui1,*, Yijing Liao1,*, Yaojing Jiang1, Xiaohang Huang2, Weihong Tao², Quanquan Zhou², Anna Shao²,

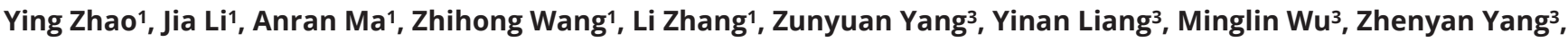 \\ Wen Zeng 3 and Qinghua Wang1,2,4
}

\author{
1Department of Endocrinology and Metabolism, Huashan Hospital, Fudan University, Shanghai, China \\ 2Shanghai Yinuo Pharmaceutical Co., Ltd., Shanghai, China \\ 3Primed Non-Human Primate Research Centre (Sichuan Primed Shines Bio-tech Co., Ltd.), Chengdu, Sichuan, China \\ 4Keenan Research Centre for Biomedical Science, Division of Endocrinology and Metabolism, St. Michael's Hospital, Toronto, Ontario, Canada
}

Correspondence should be addressed to Q Wang: Qinghua.Wang@unityhealth.to

*(Q Cui and Y Liao contributed equally to this work)

\begin{abstract}
Glucagon-like peptide 1 (GLP-1) is an insulinotropic hormone and plays an important role in regulating glucose homeostasis. GLP-1 has a short half-life $\left(\mathrm{t}_{1 / 2}<2 \mathrm{~min}\right)$ due to degrading enzyme dipeptidyl peptidase-IV and rapid kidney clearance, which limits its clinical application as a therapeutic reagent. We demonstrated recently that supaglutide, a novel GLP-1 mimetic generated by recombinant fusion protein techniques, exerted hypoglycemic and $\beta$-cell trophic effects in type 2 diabetes $\mathrm{db} / \mathrm{db}$ mice. In the present study, we examined supaglutide's therapeutic efficacy and pharmacokinetics in diabetic rhesus monkeys. We found that a single subcutaneous injection of supaglutide of tested doses transiently and significantly reduced blood glucose levels in a dose-dependent fashion in the diabetic monkeys. During a 4-week intervention period, treatment of supaglutide of weekly dosing dose-dependently decreased fasting and random blood glucose levels. This was associated with significantly declined plasma fructosamine levels. The repeated administration of supaglutide remarkably also decreased body weight in a dose-dependent fashion accompanied by decreased food intake. Intravenous glucose tolerance test results showed that supaglutide improved glucose tolerance. The intervention also showed enhanced glucose-stimulated insulin secretion and improved lipid profile in diabetic rhesus monkeys. These results reveal that supaglutide exerts beneficial effects in regulating blood glucose and lipid homeostasis in diabetic rhesus monkeys.
\end{abstract}
Key Words
- GLP-1
- supaglutide
- diabetes
- glucose homeostasis
- obesity

\section{Introduction}

Glucagon-like peptide 1 (GLP-1) is an incretin hormone produced and secreted by intestinal $\mathrm{L}$ cells in response to nutrients ingestion. GLP-1 regulates glucose metabolism mainly by stimulating postprandial insulin secretion and suppressing glucagon release (Drucker et al. 1987,
Ritzel et al. 1995, Drucker 2018, Muller et al. 2019). GLP-1 also decreases gastric emptying, inhibits food intake, and modulates rodent $\beta$-cell proliferation (Li et al. 2005, Brubaker 2010, Rajeev \& Wilding 2016, Taylor 2018, Holst 2020). The endogenous GLP-1 has a short 
in vivo half-life $\left(\mathrm{t}_{1 / 2}<2 \mathrm{~min}\right)$ due to proteolytic cleavage primarily by dipeptidyl peptidase-IV (DPP-IV), and rapid renal clearance, which limits its therapeutic potential of native GLP-1 (Orskov et al. 1993, Deacon et al. 1995, Drucker 2018, 2020). To circumvent this limitation, great efforts have been made in the past decade to prolong the in vivo GLP-1 action and two therapeutic strategies that are developed and clinically accessible: one is the use of DPP-IV inhibitors, and the other is the development of DPP-IV-resistant long-acting GLP-1 mimetics (Drucker \& Nauck 2006, Drucker 2018). There are clinically available GLP-1 receptor agonists (GLP-1RAs). According to their half-life and amino acid sequence homology with human counterparts, GLP-1RAs can be divided into short-term and long-term, animal-derived and human-derived (Uccellatore et al. 2015), which show distinguished pharmacokinetic and pharmacodynamic characteristics as well as clinical compliance (Campbell \& Drucker 2013, Gentilella et al. 2019, Overgaard et al. 2019). It is noted, long-last and human-derived rather than animal-derived either short- or long-lasting (Holman et al. 2017, Bethel et al. 2020) GLP-1RAs showed significant cardiac and renal beneficial effects (Marso et al. 2016a,b, Mann et al. 2017, Gerstein et al. 2019).

Supaglutide is a novel long-acting human-derived GLP-1RAs, produced by recombinant fusion protein techniques. This human-derived GLP-1 fusion protein contains two GLP-1 molecules with an immunoglobulin IgG2 constant region and partial hinge chains to form a spatial structure of ligand-receptor binding (Kumar et al. 2007, Soltani et al. 2007, Wang et al. 2010). Our previous studies under in vitro and in vivo conditions showed that supaglutide was relatively resistant to DPP-IV enzymatic degradation and delayed renal clearance rate due to enlarged molecular mass (>60 kDa), retaining native GLP-1 biological activities (Wang et al. 2010).

We demonstrated recently that supaglutide stimulates insulin secretion in mouse and human islet $\beta$-cells, and enlarges $\beta$-cell mass, and improves glucose homeostasis in diabetic $\mathrm{db} / \mathrm{db}$ mice (Ren et al. 2019). We also showed recently that supaglutide exerts a beneficial effect on established obesity in mice induced by high-fat diet feeding through reducing energy intake while enhancing brown remodeling of white adipose tissue via uncoupling protein 1 (Ucp1) dependent signaling pathway(Wan et al. 2017). In the present study, we investigated the therapeutic efficacy of supaglutide and pharmacokinetics in diabetic rhesus monkeys.

\section{Materials and methods}

\section{Animals}

Male rhesus monkeys with spontaneous type 2 diabetes were provided and housed in Sichuan Primed Shines Biotech Co., Ltd. (SPSB). Before the experiments, the animals were quarantined and received a physical examination, two tuberculosis (TB) tests, and tests for parasite, Salmonella, Klebsiella and B virus. Thirty-five qualified animals were screened according to guidelines for the development and management of a colony of monkeys with naturally occurring type 2 diabetes (Hansen 2012).

\section{Exclusion criteria}

Monkeys met the following exclusion criteria were excluded: type 1 diabetes, pancreatitis, diabetic ketoacidosis, chronic gastrointestinal diseases, obvious hematological diseases, severe trauma and infection.

\section{Inclusion criteria}

Monkeys were examined for intravenous glucose tolerance test (IVGTT) and insulin levels during IVGTT. Monkeys did not receive any drug treatment within 1 year after the onset of either impaired glucose tolerance (IGT), or impaired fasting glucose (IFG), or obvious hyperglycemia were selected, excluding those with advanced type 2 diabetes (Hansen 2012). During the adaptation period, male rhesus monkeys were selected with the age of 8-21 years, body weight ranging from $9.25-15.70 \mathrm{~kg}$, fasting plasma glucose (FPG): $5.50-8.58 \mathrm{mmol} / \mathrm{L}$, glycosylated hemoglobin $(\mathrm{HbA} 1 \mathrm{c})$ : 4.5-5.0\%, with normal liver and kidney functions. The animals were randomly divided into placebo and intervention groups.

\section{Feeding conditions}

Monkeys were housed under controlled temperature, $12 \mathrm{~h}$ light:12 h darkness cycle, humidity of $40-70 \%$, ventilation of fresh air at least eight times per hour, with free access to food and water. In addition to the chow diet (Primed Monkey Chow 4\#, containing 18\% proteins, $\sim 12 \%$ fat, $\sim 62 \%$ carbohydrate), monkeys were provided with $100 \mathrm{~g}$ of green feed (fruits and vegetables) every day. As a reward after domestication, snacks such as peanuts, melon seeds and other nuts are also provided. Two weeks prior to experiments, animals were domesticated for quiet and volunteer to reach out for blood collection (one to three times/week). Animal care procedures were https://joe.bioscientifica.com https://doi.org/10.1530/JOE-20-0255 (c) 2021 Society for Endocrinology Published by Bioscientifica Ltd. Printed in Great Britain 
approved by the Institutional Animal Care and Utilization Committee (IACUC) of SPSB accredited by the Association for Assessment and Accreditation of Laboratory Animal Care International (AAALAC International).

\section{Supaglutide treatment}

A pilot efficacy study was conducted in 6 diabetic rhesus monkeys divided into three dosing groups. Animals have received one subcutaneous (SC) injection of supaglutide $(25,50$ and $100 \mu \mathrm{g} / \mathrm{kg}, n=2)$, self-baseline as a control, and monitoring FPG, random plasma glucose (RPG), body weight, and food intake during a follow-up period of 14 days. In the pharmacodynamic study of multiple administration, 15 rhesus monkeys with type 2 diabetes were randomly divided into three groups $(0,25,50 \mu \mathrm{g} / \mathrm{kg}$, $n=5$ ). Supaglutide (placebo as the control) was injected subcutaneously once a week, four times in total, followed by a washing period of 15 days. FPG, RPG, fructosamine (FRA), HbA1c, fasting plasma insulin (FPI), random plasma insulin (RPI), body weight, and food intake were monitored. IVGTT was conducted on the third day after the last injection. Figure 1 shows the experimental design, showing the injection time and the blood sampling time points used for laboratory examinations.

\section{Intravenous glucose tolerance test (IVGTT)}

After $12 \mathrm{~h}$ of overnight fasting, monkeys were anesthetized with ketamine hydrochloride $(10 \mathrm{mg} / \mathrm{kg}$ ) by intramuscular injection. In total, $50 \%$ glucose solution $(0.25 \mathrm{~g} / \mathrm{kg})$ was injected into the lower extremity vein. Blood samples were collected through the forearm vein of the monkey at 3, 5, 7, 10, 20, 30 and 60 min after glucose injection. Blood samples were taken twice, 5 and $3 \mathrm{~min}$ before glucose injection as baseline control.

Glucose-stimulated insulin secretion (GSIS) was evaluated by measuring plasma insulin levels during IVGTT at the time points as indicated.
We calculated area under glycemic curve $\left(\right.$ AUC $_{\text {Glu0-60min }}$ ), glucose disposal rate (GDR) (Jen \& Hansen 1988) during the IVGTT. Acute insulin response (AIR) was estimated by calculating the average concentrations of the plasma insulin from 3 to $10 \mathrm{~min}$ after the glucose bolus. Homeostatic model assessment for $\beta$-cell function (HOMA- $\beta$ ) and for insulin resistance (HOMA-IR) was estimated by equations: HOMA- $\beta=20 \times$ FINS/(FPG-3.5) and HOMA-IR $=$ FPG $\times$ FINS/22.5, respectively, and FINS denoted fasting insulin levels.

\section{Serology studies}

Blood samples were collected by EDTA-2K anticoagulant vacuum tube $\left(13 \times 75 \mathrm{~mm}, 3.0 \mathrm{~mL} \mathrm{BD}\right.$ Vacutainer ${ }^{\circledR}$ plastic whole blood tube containing $3.4 \mathrm{mg}$ of spraycoated K2EDTA) and centrifuged at $1600 \boldsymbol{g}$ for $10 \mathrm{~min}$ at $4^{\circ} \mathrm{C}$. Plasma glucose was detected by Roche Cobas 6000 analyzer series C501 (Roche Diagnostics GmbH), and plasma insulin by Roche Cobas 6000 analyzer series E601 (Roche Diagnostics GmbH). HbA1c was detected by Siemens DCA vantage glycosylated hemoglobin analyzer. Roche Cobas 6000 analyzer series C501/E601 was used to detect FRA and other blood biochemical tests including triglyceride (TG), total cholesterol (TC), high-density lipoprotein (HDL), low-density lipoprotein (LDL), alanine aminotransferase (ALT), aspartate aminotransferase (AST), total bilirubin (TBIL), blood urea nitrogen (BUN), creatinine $(\mathrm{Cr})$ and creatine kinase $(\mathrm{CK})$.

\section{Metabolic measurements}

Food intake was measured and calculated (food intake $=$ feed - discard - surplus) during the entire study period. Four feedings of total 300-600 g feeds were made every day (09:00, 10:30, 15:00 and 16:30). Body weight measuring times: once in the adaptation period (before grouping), four times in the administration observation period (D7, D14, D21 and D28), and twice in the washout

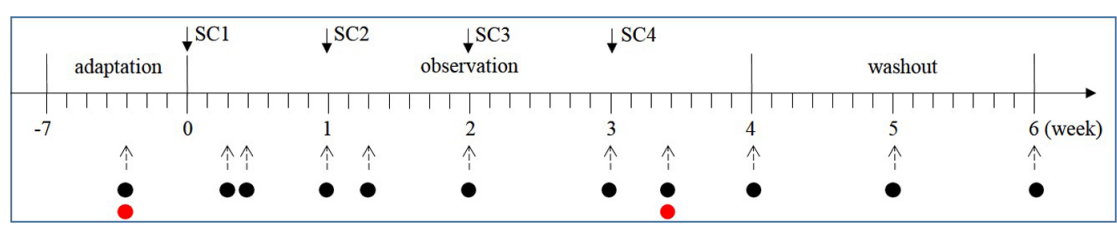

\section{Figure 1}

Supaglutide treatment design. The experiment is consisted of three periods: adaptation (43 days), observation ( 28 days) and washout (15 days). The solid arrows indicate the time points of drug injection. The dotted arrows indicate time points of blood sampling for PK (black dots) and other laboratory examinations as indicated. The red dots indicate the time points for the intravenous glucose tolerance test (IVGTT). https://joe.bioscientifica.com https://doi.org/10.1530/JOE-20-0255 (c) 2021 Society for Endocrinology Published by Bioscientifica Ltd.
Printed in Great Britain 
period (D35 and D42), a total of seven times, using METTLER TOLEDO electronic platform scale.

\section{Detection of plasma drug concentration}

Supaglutide of monkey blood samples was determined by ELISA, using primary monoclonal mouse anti-GLP-1 (Bronner et al. 2015) (Abcam, lot\# GR305368-1), and secondary antibody horseradish peroxidase-labeled goat anti-human IgG (Fc) (Thermo, lot\# QK2117736), and detected by TMB Colorimetric Kit (Thermo, lot\# RJ2281281). Optical density measurements are taken at $630 \mathrm{~nm}$ using SpectraMax 340PC384 microplate reader (Molecular Device, Sunnyvale, CA, USA) and the reading compared to a calibration curve, according to manufacturer instructions. The standard drug samples of all concentration points were prepared from $100 \%$ rhesus monkey plasma. The quantitative range of the analytical method was $3.91-500.00 \mathrm{ng} / \mathrm{mL}$. The concentration of the samples tested as well as drug concentration were automatically calculated by Watson LIMS v.7.3.0.01 (Thermo Scientific Inc.) according to the standard curve.

\section{Statistical analysis}

Statistical analysis was performed using Microsoft Office Excel, IBM SPSS Statistics V22.0, and GraphPad Prism 6 (GraphPad Software). Student's t-test or one-way ANOVA or two-way ANOVA with Dunnett post hoc test were used as appropriate. Pharmacokinetic parameters calculation and statistical analysis were made by the non-chamber model of WinNonLin v6.4 (Certara Corp.); the serum drug concentration values of all individuals less than the lowest concentration of the standard curve (LLOQ, 3.91 $\mathrm{ng} / \mathrm{mL}$ ) were recorded as below the quantification limit of the assay (BQL) when pharmacokinetic parameters were calculated. Data are mean \pm s.E.M. $P$ values $<0.05$ are considered significant.

\section{Results}

\section{Long-term treatment of supaglutide reduces blood glucose, circulating insulin and body weight}

Pilot studies exploring effective dosing showed that a single SC injection of supaglutide decreased FPG (Fig. 2A and Supplementary Table 1 , see section on supplementary materials given at the end of this article) and RPG (Fig. 2B and Supplementary Table 1) levels. Within the testing dose range $(25,50,100 \mu \mathrm{g} / \mathrm{kg})$, the effect appears to be doserelated. The single SC injection also reduced body weight (Fig. 2C and Supplementary Table 1) and food intake (Fig. 2D and Supplementary Table 1). The clinical indexes of those diabetic monkeys were shown in Supplementary Table 2. It is worth noting that from the first day to the second day after the injection, subjects receiving high
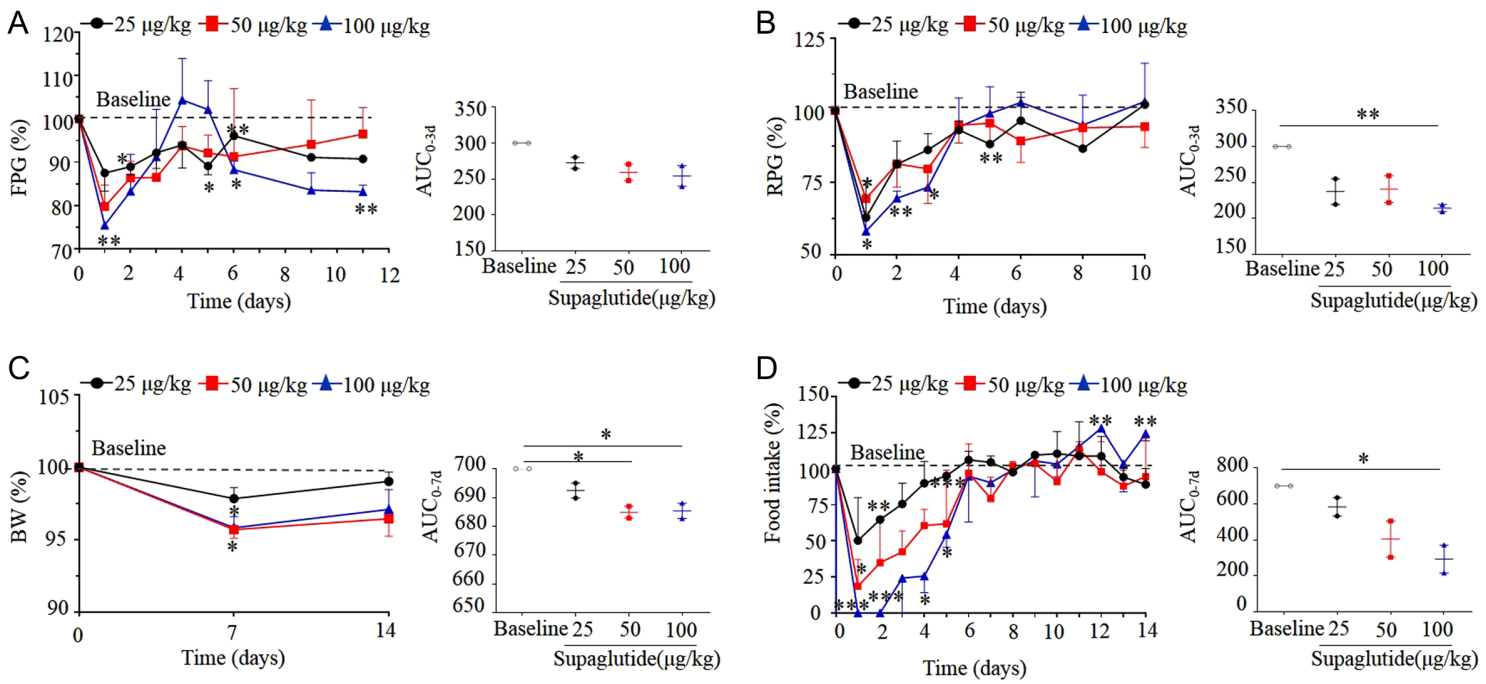

Figure 2

A single subcutaneous injection of supaglutide reduces blood glucose, food intake and body weight. (A) Changes of fasting plasma glucose (FPG) and (B) random plasma glucose (RPG) in diabetic rhesus monkeys during the treatment of supaglutide. Baseline ranges of FPG and RPG were 5.04-9.86 mmol/L, and 5.21-23.35 mmol/L, respectively. (C) Changes of body weight and (D) food intake and after a single subcutaneous injection of supaglutide. The areas under curves (AUC) are shown in the right panels. Data are shown as mean \pm S.E.M. $* P<0.05, * \star P<0.01, * \star \star P<0.001(n=2)$. 
A

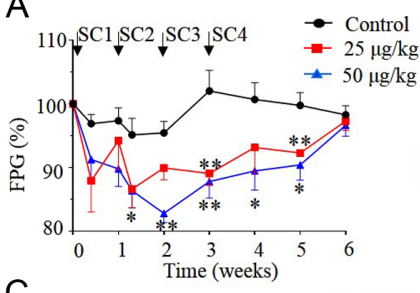

C
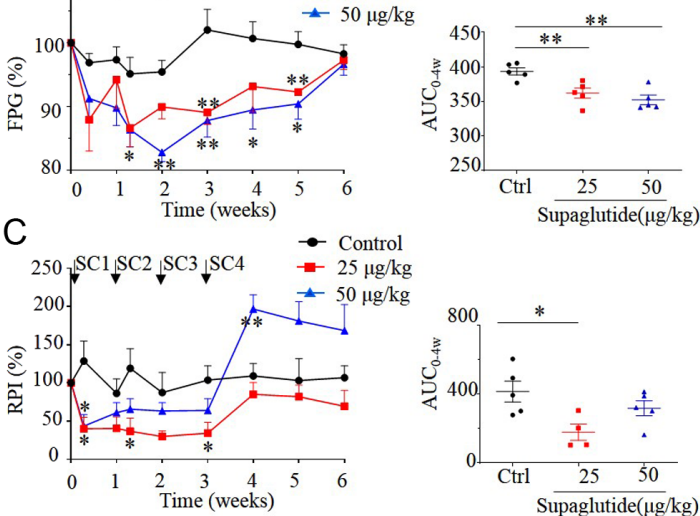

E
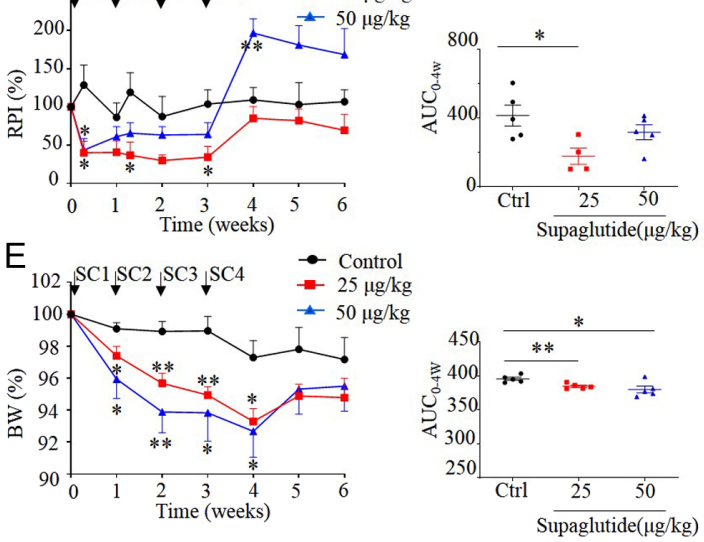

B

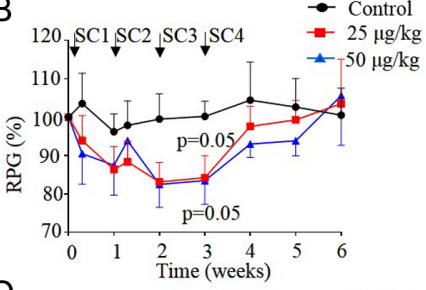

D
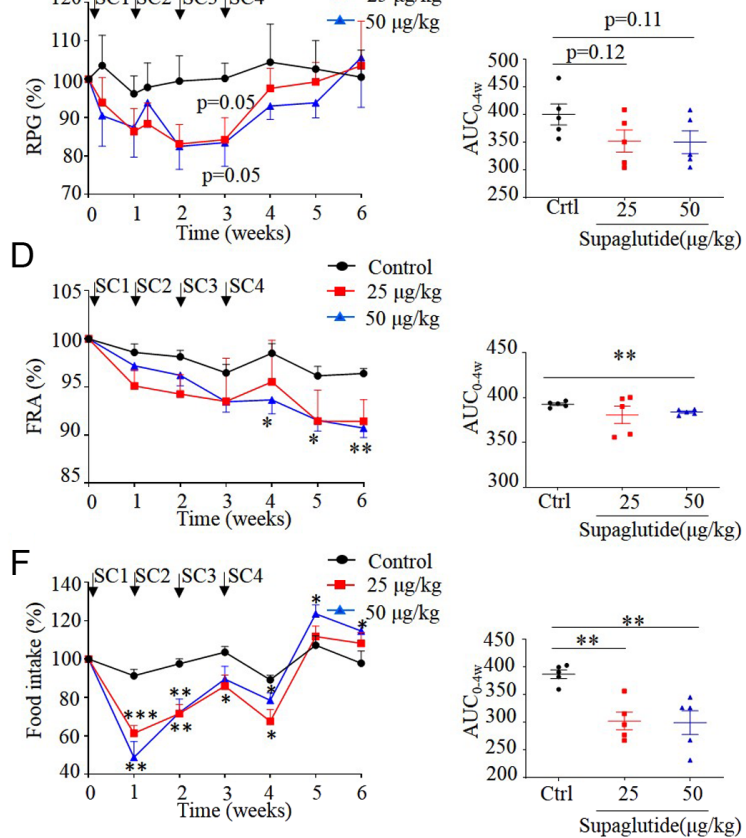

Figure 3

Long-term supaglutide treatment dose-dependently reduces blood glucose, insulin levels, body weight and food intake. (A) Change of fasting plasma glucose (FPG) and (B) random plasma glucose (RPG) in diabetic rhesus monkeys during the treatment of supaglutide or placebo. Baseline ranges of FPG and RPG were 5.38-7.25 mmol/L, and 4.5-6.72 mmol/L, respectively. (C) Changes of random plasma insulin (RPI). (D) Changes of fructosamine (FRA) from baselines. Changes of body weight (E) and food intake (F). The areas under curves (AUC) are shown in the right panels. Data are shown as mean \pm S.E.M. SC, subcutaneous of supaglutide. $* P<0.05, * * P<0.01, * \star * P<0.001(n=5)$.

doses $(100 \mu \mathrm{g} / \mathrm{kg})$ did not eat chow diet, although they did not refuse fruits and vegetables provided daily, indicating that $100 \mu \mathrm{g} / \mathrm{kg}$ of supaglutide strongly inhibited the appetite of obese monkeys. The monkeys regained their appetite on the third day after the injection.

We then examined the hypoglycemic effect of two doses of supaglutide $(25,50 \mu \mathrm{g} / \mathrm{kg})$ by repeatedly SC injections dosing weekly, for 4 weeks and a subsequent follow-up of 2 weeks. The results showed that long-term treatment of supaglutide markedly reduced FPG and RPG in a dose-related pattern (Fig. 3A, B and Supplementary Table 3). This was associated with significantly decreased RPI levels (Fig. 3C and Supplementary Table 3) and FPI levels (Supplementary Fig. 1A and Supplementary Table 3). During the intervention, although there was no significant change in HbA1c (Supplementary Fig. 1B), the plasma FRA was significantly reduced in a dose-dependent manner (Fig. 3D and Supplementary Table 3).

There was a continuous decline in body weight during the intervention period (Fig. 3E and Supplementary Table 4). It is noted that within $24 \mathrm{~h}$ of injection, a significant reduction in food intake was observed, but recovery began the next day (Fig. 3F and Supplementary Table 4).

\section{Long-term treatment of supaglutide improves glucose tolerance, enhances glucose-stimulated insulin secretion, and $\beta$-cell function}

IVGTT was performed 3 days after the last injection (D24), and the results showed that long-term treatment of supaglutide significantly improved glucose excursion rates (Fig. 4A). GSIS evaluated by measuring insulin levels during IVGTT showed that glucose-stimulated insulin secretion, particularly the first phase was significantly increased (Fig. 4B).

Metabolic analysis, using homeostatic model assessment showed enhanced $\beta$-cell function (HOMA- $\beta$, Fig. 4C), increased acute insulin response (AIR, Fig. 4D), improved insulin resistance (HOMA-IR, Fig. 4E), and increased glucose disposal rate (GDR, Fig. 4F) in the diabetic monkeys received long-term supaglutide treatment.

\section{Supaglutide alters lipid profile in the diabetic rhesus monkeys}

The results of laboratory biochemical tests of diabetic rhesus monkey are summarized in Supplementary Table 5. After 4 weeks of repeated SC injection by weekly 
A
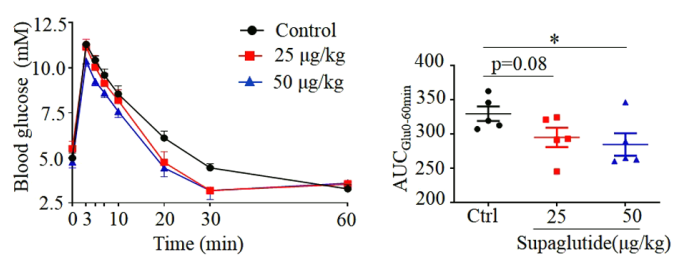

C

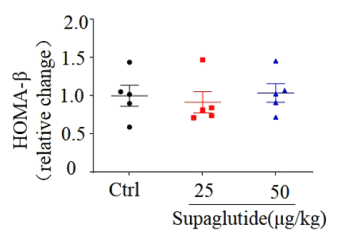

B
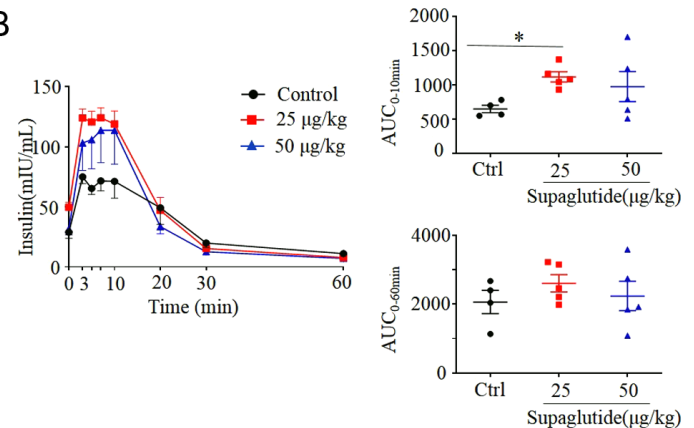

E

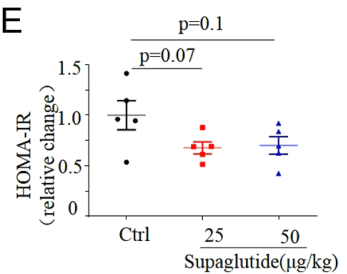

F

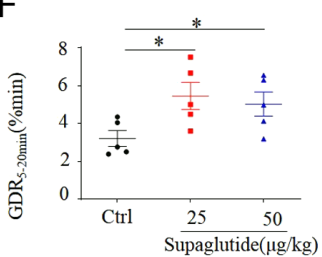

Figure 4

Long-term treatment of supaglutide improves glucose tolerance, enhances glucose-stimulated insulin secretion, and $\beta$-cell function. (A) Blood glucose levels measured during IVGTT conducted on the third day after the last injection (D24). (B) The plasma insulin levels measured during the IVGTT (D24). (C) The homeostasis model assessment- $\beta$ (HOMA- $\beta$ ). (D) The acute insulin secretion (AIR B-10min ). (E) The Homeostasis model assessment-IR (HOMA-IR). (F) The glucose disposal rate $\left(\mathrm{GDR}_{5-20 \mathrm{~min}}\right)$. The areas under curves (AUC) are shown in the right panels. Data are shown as mean \pm s.E.M. $* P<0.05(n=5)$.

dosing, supaglutide decreased total cholesterol by 27.06 and $20.85 \%$ in the monkeys received 25 and $50 \mu \mathrm{g} / \mathrm{kg}$ doses, respectively (Fig. 5A, $P=0.06, P=0.1$ ). Supaglutide also lowered LDL levels by $35 \%(25 \mu \mathrm{g} / \mathrm{kg})$ and $37 \%(50$ $\mu \mathrm{g} / \mathrm{kg}, P<0.05$ ) in the diabetes monkeys (Fig. 5B). HDL levels were not significantly changed in both dose groups (Fig. 5C).

Other biochemical indexes such as ALT, AST, BUN and $\mathrm{Cr}$ were not significantly changed in both dosing groups. Compared with baseline, supaglutide decreased CK values in both dosing group, but statistically significance only found in the $25 \mu \mathrm{g} / \mathrm{kg}$ group ( $130 \pm 13$ vs $87 \pm 3, P<0.05$ ), but not the $50 \mu \mathrm{g} / \mathrm{kg}$ group ( $93 \pm 8$ vs $76 \pm 5, P>0.05$ ). Supaglutide also decreased TBIL measurements in both dosing groups $(25 \mu \mathrm{g} / \mathrm{kg}, 2.5 \pm 0.5$ vs $1.9 \pm 0.4, P>0.05$; $50 \mu \mathrm{g} / \mathrm{kg}, 3.2 \pm 0.3$ vs $2.2 \pm 0.2, P<0.05$ ) when compared with the baseline (Supplementary Table 5), suggesting that the investigational doses of supaglutide had no adverse effect on the liver and kidney function of diabetic rhesus monkeys.

\section{Pharmacokinetic outcomes of supaglutide repeatedly injections in diabetic rhesus monkeys}

The major pharmacokinetic parameters of supaglutide in diabetic rhesus monkeys are summarized in Table 1 . The maximal concentration $\mathrm{C}_{\max }$ is 84 and $181 \mathrm{ng} / \mathrm{mL}$ for 25 and $50 \mu \mathrm{g} / \mathrm{kg}$, respectively. The time of observed
A
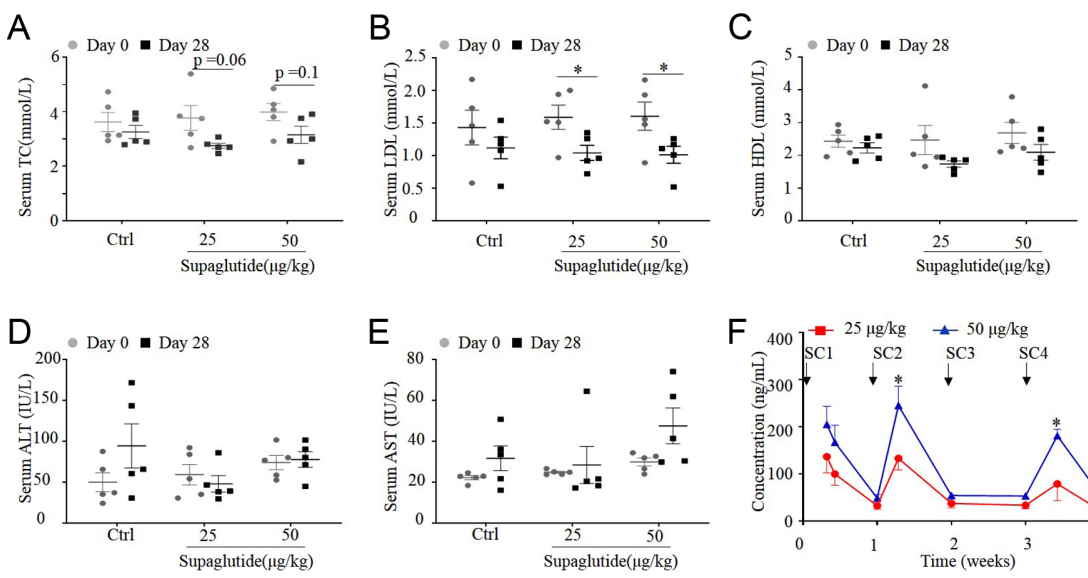

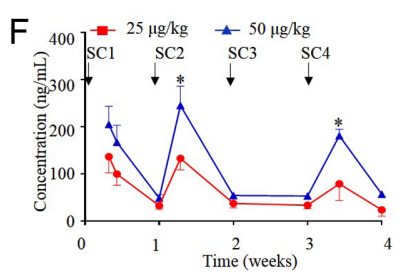

Figure 5

Supaglutide alters lipid profile in diabetic rhesus monkeys. (A) The levels of the total cholesterol (TC). (B) Low-density lipoprotein (LDL) levels. (C) High-density lipoprotein (HDL) levels. (D) The levels of the alanine aminotransferase (ALT). (E) Aspartate aminotransferase (AST) levels. Data are shown as mean \pm S.E.M. $* P<0.05(n=5)$. (F) Supaglutide blood concentrations measured during the intervention period in the blood sampled at the time points as indicated $(54,72$, $168,336,504,576$ and 672 h). Data are shown as mean \pm S.E.M. SC, subcutaneous of supaglutide. $\star P<0.05(n=3)$. 
Table 1 Pharmacodynamics associated with pharmacodynamics of supaglutide repeatedly injections for four times in rhesus monkeys.

\begin{tabular}{|c|c|}
\hline Dosing & $\mathbf{C}_{\max }(\mathrm{ng} / \mathrm{mL})$ \\
\hline $25 \mu \mathrm{g} / \mathrm{kg}$ & $84.01 \pm 31.39$ \\
\hline $50 \mu \mathrm{g} / \mathrm{kg}$ & $181.28 \pm 13.63$ \\
\hline
\end{tabular}

\begin{tabular}{c}
\hline $\mathbf{T}_{\max }(\mathrm{h})$ \\
\hline 576 \\
576 \\
\hline
\end{tabular}

$\begin{array}{r}\mathbf{A U C}_{\mathbf{0} \text {-inf }}(\mathrm{ng} / \mathrm{h} / \mathrm{mL}) \\ \hline 11,323.69 \pm 4934.76 \\ 247,979.53 \pm 1407.04 \\ \hline\end{array}$

\begin{tabular}{c}
$\frac{\mathbf{T}_{\mathbf{1 / 2}}(\mathrm{h})}{59.36 \pm 3.77}$ \\
$58.46 \pm 2.44$ \\
\hline
\end{tabular}

\begin{tabular}{c}
\hline $\mathbf{C L} / \mathbf{F}(\mathrm{mL} / \mathrm{h} / \mathrm{kg})$ \\
\hline $2.39 \mathrm{a}$ \\
$2.53 \pm 0.16$ \\
\hline
\end{tabular}

\begin{tabular}{c}
$\frac{\mathbf{v}_{\mathbf{s s}} / \mathbf{F}(\mathrm{mL} / \mathrm{kg})}{178.67 \mathrm{a}}$ \\
$214.22 \pm 20.78$ \\
\hline
\end{tabular}

Data are shown as mean \pm S.E.M.

aMedian.

AUC, area under the curve; $\mathrm{C}_{\max }$ maximum plasma concentration; $\mathrm{CL} / \mathrm{F}$, clearance/fraction absorbed (bioavailability); $\mathrm{T}_{\max }$ time to maximum plasma concentration; $T_{1 / 2}$, terminal half-life; $V_{S S} / F$, volume of distribution at steady-state/fraction absorbed (bioavailability).

maximal drug concentration $\mathrm{T}_{\max }$ is $576 \mathrm{~h}$. The half-life is approximately $59 \mathrm{~h}$. These data revealed that the peak concentration of supaglutide and the level of exposure increased with the increase of dose.

During the intervention, monitoring animal behavior showed no abnormal change related to administration including behavioral activities, mental state, body surface hair color, and animal feces.

\section{Discussion}

The present study demonstrates that supaglutide administrated once a week for 4 weeks significantly improved glucose homeostasis in rhesus monkeys with naturally occurred type 2 diabetes.

Single SC injection of supaglutide showed the tested doses $(25,50$ and $100 \mu \mathrm{g} / \mathrm{kg})$ that were effective in lowing both FPG and RPG associated with body weight sparing effects in a dose-dependent fashion. The efficacy peak appeared at $24 \mathrm{~h}$ after the injection and it continued for about a week and gradually returned to the basal levels. Weight loss is one recognized efficacy of GLP-1 therapy (Drucker 2018). A significant reduction in food intake in dose-dependent manner was noted. Within the first $48 \mathrm{~h}$ after the high dose injection $(100 \mu \mathrm{g} / \mathrm{kg})$, animals were reluctant to chow diet, indicating strongly inhibited appetite, although they did not refuse fruits and vegetables, and regained their appetite on the third day after the injection. Our observations are consistent with previous studies demonstrating that therapies with GLP-1RAs, that is, exendin-4 (Scott \& Moran 2007), and/or dulaglutide (Vahle et al. 2015) significantly and dose-dependently reduced food intake and body weight in non-diabetic rhesus monkeys.

Repeated administration with weekly dosing (25, $50 \mu \mathrm{g} / \mathrm{kg}$ ), supaglutide reached a steady state of blood concentration after the second injections. The observed decrease in FPG and RPG levels was accompanied by a decrease in FPI and RPI levels. Type 2 diabetes is usually associated with obesity and insulin resistance which is characterized by basal hyperinsulinemia (Shanik et al. 2008). Obese diabetic monkeys treated with supaglutide displayed improved blood glucose and increased glucosestimulated insulin secretion (during IVGTT). Therefore, it is likely, the decreased fasting insulin (and RPI) may be attributed to improved glycemic control that leading to decreased demand for insulin (Hasnain et al. 2014). In addition, the improvement of obesity may also contribute to the decrease of basal insulin (Shanik et al. 2008). Since we did not perform ITT or hyperinsulinemic normoglycemic clamp, and we are unable to directly address whether supaglutide therapy improved insulin sensitivity in these diabetic monkeys. Nevertheless, our observations are consistent with other's study demonstrating that treatment with GLP-1RA liraglutide produced beneficial effects on hyperglycemia and insulin sensitivity parameters (i.e. HOMA-IR and HOMA- $\beta$ ) in patients with type 2 diabetes (Díaz-Soto et al. 2014). It is interesting to note, although the causal relationships between insulin levels and insulin resistance are not fully elucidated, a number of studies showed that improved insulin sensitivity is associated with reduced fasting glucose and decreased insulin levels in mice (Templeman et al. 2017), non-human primates (Henderson et al. 2016) and humans (Wang et al. 2018, Contreras et al. 2019). On the other hand, elevated insulin contributes to insulin resistance (Templeman et al. 2017).

During the intervention period of 4 weeks, although HbA1c was not obviously changed, the plasma FRA, a validated-biomarker that reflects the average levels of glucose control over the past 2-3 weeks (Ren et al. 2019, Calderon et al. 2020), was significantly decreased, in a dose-dependent fashion. The metabolic cycle of erythrocytes in rhesus monkeys is about 90 days (Pasini et al. 2010). HbA1c of rhesus monkey is used to evaluate the blood glucose level over the past 2-3 months.

Compared with the placebo control, repeated injections with weekly dosing $(25,50 \mu \mathrm{g} / \mathrm{kg})$ significantly reduced body weight in dose-dependent fashion, 
which was accompanied by significantly decreased food intake in these obese diabetic monkeys. Reduction in body weight may be a consequence of lower food intake and/or enhanced energy expenditure. It is worth noting that during the intervention period, the body weight significantly and continuously decreased within $48 \mathrm{~h}$ after the first injection, but reached the plateau period after the second injection. This is in contrast to the significant reduction in food intake within $24 \mathrm{~h}$ after the first injection and recovery from the next day, suggesting that the weight loss may also be contributed by factors other than food intake, possibly due to changes in energy expenditure. Our recent study showed that in obese mice repeated injections of supaglutide significantly promoted body weight loss associated with increased energy expenditure (Wan et al. 2017). This is consistent with other's observations that in diet-induced obese mice and non-human primates, GLP-1 based therapy significantly reduced blood glucose, and reduced body weight mainly due to the increased lipid and carbohydrate oxidation and energy consumption (Elvert et al. 2018).

Supaglutide treatment improved glucose tolerance associated with improved $\beta$-cell function, exemplified by enhanced insulin secretion, particularly in the first phase during IVGTT in diabetic monkeys, consistent with our recent data showing that long-term treatment with supaglutide stimulates insulin secretion and enlarges $\beta$-cell mass in diabetic $\mathrm{db} / \mathrm{db}$ mice (Ren et al. 2019).

Numerous evidence showing that GLP-1/GLP-1RAs stimulates insulin secretion and enhances $\beta$-cell mass in rodents (Lee \& Jun 2014, Kawamori et al. 2017, Muller et al. 2019). However, whether incretin-based therapies sustain functional $\beta$-cell mass in human diabetic subjects remains unclear (Drucker 2013). Clinical studies demonstrated that GLP-1RAs enhance $\beta$-cell function and improve insulin resistance (Mari et al. 2007). Non-human primate islets are morphologically and structurally similar to human islets (Mohanasundaram et al. 2011), and there is experimental evidence of islet regeneration and restoration of $\beta$-cell mass in non-human primates under the condition of $\beta$-cell injury (Chen et al. 2014).

In summary, our results suggest that the human origin long-lasting GLP-1R agonist supaglutide by weekly dosing in diabetic rhesus monkeys exerts long-lasting hypoglycemic effects associated with enhanced $\beta$-cell function, and body weight sparing effects. The prolonged half-life and metabolically beneficial effect of supaglutide provides an alternative new tool in studying GLP-1 biology and potentially alternative therapy to treat type 2 diabetes and its associated metabolic disorders.

\section{Supplementary materials}

This is linked to the online version of the paper at https://doi.org/10.1530/ JOE-20-0255.

\section{Declaration of interest}

The authors declare that there is no duality of interest associated with this manuscript. Q W has GLP-1 related patents.

\section{Funding}

This project was partially supported by grants from the Ministry of Science and Technology (No. 2011ZX09102, No. 2017ZX09303001), Shanghai Science and Technology Department (No. 2017ZX09303001), and Yunnan Provincial Science and Technology Department, Yunnan Development and Reform Commission, Kunming Municipal Bureau of Human Resources and Social Security.

\section{Author contribution statement}

W Z and Q W contributed to the conception and design of the study. $Z$ Y, $Y L, M W, Z Y$ and $W Z$ contributed to performing the major body of the experiments. $X \mathrm{H}, \mathrm{W} T, \mathrm{Q} Z$ and $\mathrm{A}$ S contributed to supaglutide production. $Q$ C, Y L, A M, Y J, Y Z, J L, Z W, and L Z analyzed the data. Y L, Y J, Q C and Q W contributed to writing manuscript. All authors reviewed and proved the manuscript.

\section{References}

Bethel MA, Mentz RJ, Merrill P, Buse JB, Chan JC, Goodman SG, Iqbal N, Jakuboniene N, Katona B, Lokhnygina Y, et al. 2020 Microvascular and cardiovascular outcomes according to renal function in patients treated with once-weekly exenatide: insights from the EXSCEL Trial. Diabetes Care 43 446-452. (https://doi.org/10.2337/dc19-1065)

Bronner DN, Abuaita BH, Chen X, Fitzgerald KA, Nunez G, He Y, Yin XM \& O'riordan MX 2015 Endoplasmic reticulum stress activates the inflammasome via NLRP3- and caspase-2-driven mitochondrial damage. Immunity 43 451-462. (https://doi.org/10.1016/j. immuni.2015.08.008)

Brubaker PL 2010 Minireview: update on incretin biology: focus on glucagon-like peptide-1. Endocrinology 151 1984-1989. (https://doi org/10.1210/en.2010-0115)

Calderon G, Mcrae A, Rievaj J, Davis J, Zandvakili I, Linker-Nord S, Burton D, Roberts G, Reimann F, Gedulin B, et al. 2020 Ileo-colonic delivery of conjugated bile acids improves glucose homeostasis via colonic GLP-1-producing enteroendocrine cells in human obesity and diabetes. EBiomedicine 55 102759. (https://doi.org/10.1016/j. ebiom.2020.102759)

Campbell JE \& Drucker DJ 2013 Pharmacology, physiology, and mechanisms of incretin hormone action. Cell Metabolism 17 819-837. (https://doi.org/10.1016/j.cmet.2013.04.008)

Chen S, Bastarrachea RA, Roberts BJ, Voruganti VS, Frost PA, NavaGonzalez EJ, Arriaga-Cazares HE, Chen J, Huang P, Defronzo RA, et al. 2014 Successful $\beta$ cells islet regeneration in streptozotocin-induced diabetic baboons using ultrasound-targeted microbubble gene therapy with cyclinD2/CDK4/GLP1. Cell Cycle 13 1145-1151. (https://doi. org/10.4161/cc.27997)

Contreras PH, Salgado AM, Bernal YA \& Vigil P 2019 A simple and improved predictor of insulin resistance extracted from the oral 
glucose tolerance test: the $\mathrm{I0}{ }^{*} \mathrm{G} 60$. Journal of the Endocrine Society 3 1154-1166. (https://doi.org/10.1210/js.2018-00342)

Deacon CF, Nauck MA, Toft-Nielsen M, Pridal L, Willms B \& Holst JJ 1995 Both subcutaneously and intravenously administered glucagonlike peptide I are rapidly degraded from the NH2-terminus in type II diabetic patients and in healthy subjects. Diabetes 44 1126-1131. (https://doi.org/10.2337/diab.44.9.1126)

Díaz-Soto G, De Luis DA, Conde-Vicente R, Izaola-Jauregui O, Ramos C \& Romero E 2014 Beneficial effects of liraglutide on adipocytokines, insulin sensitivity parameters and cardiovascular risk biomarkers in patients with Type 2 diabetes: a prospective study. Diabetes Research and Clinical Practice 104 92-96. (https://doi.org/10.1016/j. diabres.2014.01.019)

Drucker DJ 2013 Incretin action in the pancreas: potential promise, possible perils, and pathological pitfalls. Diabetes 62 3316-3323. (https://doi.org/10.2337/db13-0822)

Drucker DJ 2018 Mechanisms of action and therapeutic application of glucagon-like peptide-1. Cell Metabolism 27 740-756. (https://doi. org/10.1016/j.cmet.2018.03.001)

Drucker DJ 2020 Advances in oral peptide therapeutics. Nature Reviews: Drug Discovery 19 277-289. (https://doi.org/10.1038/s41573-0190053-0)

Drucker DJ \& Nauck MA 2006 The incretin system: glucagon-like peptide- 1 receptor agonists and dipeptidyl peptidase- 4 inhibitors in type 2 diabetes. Lancet 368 1696-1705. (https://doi.org/10.1016/ S0140-6736(06)69705-5)

Drucker DJ, Philippe J, Mojsov S, Chick WL \& Habener JF 1987 Glucagonlike peptide I stimulates insulin gene expression and increases cyclic AMP levels in a rat islet cell line. PNAS 84 3434-3438. (https://doi. org/10.1073/pnas.84.10.3434)

Elvert R, Herling AW, Bossart M, Weiss T, Zhang B, Wenski P, Wandschneider J, Kleutsch S, Butty U, Kannt A, et al. 2018 Running on mixed fuel-dual agonistic approach of GLP-1 and GCG receptors leads to beneficial impact on body weight and blood glucose control: a comparative study between mice and non-human primates. Diabetes, Obesity and Metabolism 20 1836-1851. (https://doi. org/10.1111/dom.13212)

Gentilella R, Pechtner V, Corcos A \& Consoli A 2019 Glucagon-like peptide- 1 receptor agonists in type 2 diabetes treatment: are they all the same? Diabetes/Metabolism Research and Reviews 35 e3070. (https:// doi.org/10.1002/dmrr.3070)

Gerstein HC, Colhoun HM, Dagenais GR, Diaz R, Lakshmanan M, Pais P, Probstfield J, Riesmeyer JS, Riddle MC, Ryden L, et al. 2019 Dulaglutide and cardiovascular outcomes in type 2 diabetes (REWIND): a double-blind, randomised placebo-controlled trial. Lancet 394 121-130. (https://doi.org/10.1016/S0140-6736(19) 31149-3)

Hansen BC 2012 Investigation and treatment of type 2 diabetes in nonhuman primates. Methods in Molecular Biology 933 177-185. (https://doi.org/10.1007/978-1-62703-068-7_11)

Hasnain SZ, Borg DJ, Harcourt BE, Tong H, Sheng YH, Ng CP, Das I, Wang R, Chen AC, Loudovaris T, et al. 2014 Glycemic control in diabetes is restored by therapeutic manipulation of cytokines that regulate beta cell stress. Nature Medicine 20 1417-1426. (https://doi. org/10.1038/nm.3705)

Henderson SJ, Konkar A, Hornigold DC, Trevaskis JL, Jackson R, Fritsch Fredin M, Jansson-Löfmark R, Naylor J, Rossi A, Bednarek MA, et al. 2016 Robust anti-obesity and metabolic effects of a dual GLP-1/ glucagon receptor peptide agonist in rodents and non-human primates. Diabetes, Obesity and Metabolism 18 1176-1190. (https://doi. org/10.1111/dom.12735)

Holman RR, Bethel MA, Mentz RJ, Thompson VP, Lokhnygina Y, Buse JB, Chan JC, Choi J, Gustavson SM, Iqbal N, et al. 2017 Effects of onceweekly exenatide on cardiovascular outcomes in Type 2 diabetes. New England Journal of Medicine 377 1228-1239. (https://doi.org/10.1056/ NEJMoa1612917)
Holst JJ 2020 Incretin therapy for diabetes mellitus type 2. Current Opinion in Endocrinology, Diabetes, and Obesity 27 2-10. (https://doi. org/10.1097/MED.0000000000000516)

Jen KC \& Hansen BC 1988 Glucose disappearance rate in rhesus monkeys: some technical considerations. American Journal of Primatology 14 153-166. (https://doi.org/10.1002/ajp.1350140206)

Kawamori D, Shirakawa J, Liew CW, Hu J, Morioka T, Duttaroy A, Burkey B \& Kulkarni RN 2017 GLP-1 signalling compensates for impaired insulin signalling in regulating beta cell proliferation in $\beta$ IRKO mice. Diabetologia 60 1442-1453. (https://doi.org/10.1007/ s00125-017-4303-6)

Kumar M, Hunag Y, Glinka Y, Prud'homme GJ \& Wang Q 2007 Gene therapy of diabetes using a novel GLP-1/IgG1-Fc fusion construct normalizes glucose levels in $\mathrm{db} / \mathrm{db}$ mice. Gene Therapy 14 162-172. (https://doi.org/10.1038/sj.gt.3302836)

Lee YS \& Jun HS 2014 Anti-diabetic actions of glucagon-like peptide-1 on pancreatic beta-cells. Metabolism: Clinical and Experimental 63 9-19. (https://doi.org/10.1016/j.metabol.2013.09.010)

Li Y, Cao X, Li LX, Brubaker PL, Edlund H \& Drucker DJ 2005 beta-Cell $\mathrm{Pdx} 1$ expression is essential for the glucoregulatory, proliferative, and cytoprotective actions of glucagon-like peptide-1. Diabetes $\mathbf{5 4}$ 482-491. (https://doi.org/10.2337/diabetes.54.2.482)

Mann JFE, Orsted DD, Brown-Frandsen K, Marso SP, Poulter NR, Rasmussen S, Tornoe K, Zinman B, Buse JB \& LEADER Steering Committee and Investigators 2017 Liraglutide and renal outcomes in Type 2 diabetes. New England Journal of Medicine 377 839-848. (https://doi.org/10.1056/NEJMoa1616011)

Mari A, Degn K, Brock B, Rungby J, Ferrannini E \& Schmitz O 2007 Effects of the long-acting human glucagon-like peptide-1 analog liraglutide on beta-cell function in normal living conditions. Diabetes Care 30 2032-2033. (https://doi.org/10.2337/dc07-0310)

Marso SP, Bain SC, Consoli A, Eliaschewitz FG, Jodar E, Leiter LA, Lingvay I, Rosenstock J, Seufert J, Warren ML, et al. $2016 a$ Semaglutide and cardiovascular outcomes in patients with Type 2 diabetes. New England Journal of Medicine 375 1834-1844. (https://doi. org/10.1056/NEJMoa1607141)

Marso SP, Daniels GH, Brown-Frandsen K, Kristensen P, Mann JF, Nauck MA, Nissen SE, Pocock S, Poulter NR, Ravn LS, et al. $2016 b$ Liraglutide and cardiovascular outcomes in Type 2 diabetes. New England Journal of Medicine 375 311-322. (https://doi.org/10.1056/ NEJMoa1603827)

Mohanasundaram D, Drogemuller C, Brealey J, Jessup CF, Milner C, Murgia C, Lang CJ, Milton A, Zalewski PD, Russ GR, et al. 2011 Ultrastructural analysis, zinc transporters, glucose transporters and hormones expression in New world primate (Callithrix jacchus) and human pancreatic islets. General and Comparative Endocrinology $\mathbf{1 7 4}$ 71-79. (https://doi.org/10.1016/j.ygcen.2011.07.004)

Muller TD, Finan B, Bloom SR, D'alessio D, Drucker DJ, Flatt PR, Fritsche A, Gribble F, Grill HJ, Habener JF, et al. 2019 Glucagon-like peptide 1 (GLP-1). Molecular Metabolism 30 72-130. (https://doi. org/10.1016/j.molmet.2019.09.010)

Orskov C, Wettergren A \& Holst JJ 1993 Biological effects and metabolic rates of glucagonlike peptide-1 7-36 amide and glucagonlike peptide-1 7-37 in healthy subjects are indistinguishable. Diabetes 42 658-661. (https://doi.org/10.2337/diab.42.5.658)

Overgaard RV, Lindberg S $\varnothing$ \& Thielke D 2019 Impact on HbA1c and body weight of switching from other GLP-1 receptor agonists to semaglutide: a model-based approach. Diabetes, Obesity and Metabolism 21 43-51. (https://doi.org/10.1111/dom.13479)

Pasini EM, Kirkegaard M, Mortensen P, Mann M \& Thomas AW 2010 Deep-coverage rhesus red blood cell proteome: a first comparison with the human and mouse red blood cell. Blood Transfusion $\mathbf{8}$ (Supplement 3) s126-s139. (https://doi.org/10.2450/2010.020S)

Rajeev SP \& Wilding J 2016 GLP-1 as a target for therapeutic intervention. Current Opinion in Pharmacology 31 44-49. (https://doi.org/10.1016/j. coph.2016.08.005) 
Ren L, Cui Q, Liu W, Wang L, Liao Y, Feng Y, Sun W, Yang Y, Zhang Z, Jin T, et al. 2019 Novel GLP-1 analog supaglutide stimulates insulin secretion in mouse and human islet beta-cells and improves glucose homeostasis in diabetic mice. Frontiers in Physiology 10 930. (https:// doi.org/10.3389/fphys.2019.00930)

Ritzel R, Orskov C, Holst JJ \& Nauck MA 1995 Pharmacokinetic, insulinotropic, and glucagonostatic properties of GLP-1 [7-36 amide] after subcutaneous injection in healthy volunteers. Dose-responserelationships. Diabetologia 38 720-725. (https://doi.org/10.1007/ BF00401846)

Scott KA \& Moran TH 2007 The GLP-1 agonist exendin-4 reduces food intake in nonhuman primates through changes in meal size. American Journal of Physiology: Regulatory, Integrative and Comparative Physiology 293 R983-R987. (https://doi.org/10.1152/ ajpregu.00323.2007)

Shanik MH, Xu Y, Skrha J, Dankner R, Zick Y \& Roth J 2008 Insulin resistance and hyperinsulinemia: is hyperinsulinemia the cart or the horse? Diabetes Care 31 (Supplement 2) S262-S268. (https://doi. org/10.2337/dc08-s264)

Soltani N, Kumar M, Glinka Y, Prud'homme GJ \& Wang Q 2007 In vivo expression of GLP-1/IgG-Fc fusion protein enhances beta-cell mass and protects against streptozotocin-induced diabetes. Gene Therapy 14 981-988. (https://doi.org/10.1038/sj.gt.3302944)

Taylor SI 2018 GLP-1 receptor agonists: differentiation within the class. Lancet: Diabetes and Endocrinology 6 83-85. (https://doi.org/10.1016/ S2213-8587(17)30413-8)
Templeman NM, Flibotte S, Chik JHL, Sinha S, Lim GE, Foster LJ, Nislow C \& Johnson JD 2017 Reduced circulating insulin enhances insulin sensitivity in old mice and extends lifespan. Cell Reports 20 451-463. (https://doi.org/10.1016/j.celrep.2017.06.048)

Uccellatore A, Genovese S, Dicembrini I, Mannucci E \& Ceriello A 2015 Comparison review of short-acting and long-acting glucagon-like Peptide-1 receptor agonists. Diabetes Therapy: Research, Treatment and Education of Diabetes and Related Disorders 6 239-256. (https://doi. org/10.1007/s13300-015-0127-x)

Vahle JL, Byrd RA, Blackbourne JL, Martin JA, Sorden SD, Ryan T, Pienkowski T, Wijsman JA, Smith HW \& Rosol TJ 2015 Effects of dulaglutide on thyroid $\mathrm{C}$ cells and serum calcitonin in male monkeys. Endocrinology 156 2409-2416. (https://doi.org/10.1210/en.2014-1717)

Wan Y, Bao X, Huang J, Zhang X, Liu W, Cui Q, Jiang D, Wang Z, Liu R \& Wang Q 2017 Novel GLP-1 analog supaglutide reduces HFDinduced obesity associated with increased Ucp-1 in white adipose tissue in mice. Frontiers in Physiology 8 294. (https://doi.org/10.3389/ fphys.2017.00294)

Wang Q, Chen K, Liu R, Zhao F, Gupta S, Zhang N \& Prud'homme GJ 2010 Novel GLP-1 fusion chimera as potent long acting GLP-1 receptor agonist. PLOS ONE 5 e12734. (https://doi.org/10.1371/ journal.pone.0012734)

Wang Y, Qiao S, Han DW, Rong XR, Wang YX, Xue JJ \& Yang J 2018 Telmisartan improves insulin resistance: a meta-analysis. American Journal of Therapeutics 25 e642-e651. (https://doi.org/10.1097/ MJT.0000000000000733)

Received in final form 13 November 2020

Accepted 26 November 2020

Accepted Manuscript published online 2 December 2020 (c) 2021 Society for Endocrinology Published by Bioscientifica Ltd.
Printed in Great Britain 